\title{
Metabolic Syndrome in Childhood: defining the problem
}

\section{Şükrü Hatun}

Kocaeli University Medical School, Department of Pediatrics, Pediatric Endocrinology and Diabetes Unit, Kocaeli, Turkey

Keywords:
Metabolic syndrome,
children
Received: 09 October 2008
Accepted: 22 October 2008
Corresponding Author:
Sükrü Hatun
Kocaeli University Medical
School, Department of
Pediatrics, Pediatric
Endocrinology and Diabetes
Unit, Kocaeli, Turkey
E-mail:
sukruhatun@gmail.com

\section{ABSTRACT}

There is a significant increase in the incidence of childhood obesity all over the world which frequently leads to Type 2 diabetes mellitus (T2DM). Several studies have focused on the definitive criteria for diagnosis of childhood obesity and the assessment of risks for the future adverse developments. The identifying criteria for metabolic syndrome in children and adolescents have been developed. The factors most stressed in the pathogenesis of childhood metabolic syndrome are obesity and insulin resistance (IR). The details of the metabolic processes behind this development need still to be elucidated. This paper reviews the definition, recent diagnostic criteria, incidence and pathogenesis of metabolic syndrome in children and adolescents.

Conflict of interest: None declared

\section{INTRODUCTION}

The significant increase during the last 30 years in the incidence of childhood obesity especially in the USA, which frequently leads to Type 2 diabetes mellitus (T2DM) has drawn attention to the events underlying this progression of morbidity. Many studies with children on the characteristics and prevalence of the phenotype of the metabolic syndrome, recently accepted as the antecedent of T2DM and as a major risk of cardicovascular disease (CVD), have recently been published. The endocrinological and metabolic studies in adults evaluating visceral fat mass, blood HDL-cholesterol and triglyceride levels and insulin sensitivity have shown that they can be categorized as belonging to one of the following four different phenotypes: (i) obese' with normal weight, (iii) obese but metabolically normal, and (iv) obese under risk.(1) The similarities between this classification and the description of the metabolic syndrome point to the importance of early detection of the 'obese under risk', in childhood and adulthood, for the prevention of CVD and T2DM. The metabolic syndrome had initially been described as the combination of hyperglycemia, hypertension and hyperuricaemia. Reaven, in 1988, using the term Syndrome X, drew attention to the relationship between systemic insulin resistance (IR) and the metabolic syndrome. WHO in 1988, the National Cholesterol Education Program (NCEP) in 2001 and the International Diabetes Federation (IDF) in 2005 have offered further descriptions to the syndrome. $(2,3,4,5)$ It has been demonstrated that adults with the metabolic syn- 
drome run a 2-3 times higher risk for cardiovascular disease and stroke and are 5 times more prone to T2DM as compared to those without. It is also known that the prevalence of metabolic syndrome in the world adult population is about 25\%.(5)

Although thirty years ago in the USA obesity in children was very rare and T2DM was hardly seen, the current observations of overweight or obesity indicating a prevalence as high as one in three children in some cities and the diagnosis in pediatric endocrinology departments of T2DM in 20\% of the diabetes cases have caused amazement.(6) However, the relationship between obesity and T2DM cannot be direct or simple because among the obese adolescents which make up at least $17 \%$ of this age group in the USA, the incidence of T2DM is $<0.5 \%$. The pathogenetic relationship between obesity and T2DM has altered the view on obesity in that, although most obese children have IR of various degrees, obesity develops as part of the process leading to metabolic syndrome/prediabetes only in some, making an early recognition of this particular group under risk important.

Based on studies on children and adults, it is proposed that the progress to metabolic syndrome and T2DM is accompanied by a significant accumulation of central (visceral) fat tissue acting like "a toxic/inflammatory area" disrupting the insulin signal at the receptor and post receptor stages by releasing mediators like free fatty acids, tumor necrosis factor- $\alpha$ (TNF- $\alpha$ ), IL-6 and resistin, resulting in a vicious circle between fat tissue and insulin resistance. $(7,8)$ Whether it is obesity or IR that develops first or, put in other words, whether IR is secondary to obesity, are ongoing arguments. Information in these respects, which is useful to the understanding of processes underlying obesity/metabolic syndrome/T2DM relationships, have been obtained on "tissue- specific insulin receptor knock out" (IRKO) mice by Ron Kahn.(9) In this work, insulin receptors in 8 different tissues had been knocked out to create phenotypes. Fat tissue was found to have increased only in the liver tissue (LIRKO) and brain tissue (NIRKO) insulin receptor knocked out phenotypes, while the muscle tissue (MIRKO) and fat tissue (FIRKO) knocked out phenotypes were found to have been protected from obesity.

These models has given strong clues that in the 'obese under risk', IR starts first in the liver resulting in increased insulin secretory response and enabling the accumulation of fat, while IR starting in the central nervous system results in an increase of appetite, weight gain and peripheral IR by the antagonisation of leptin. These findings support the view that in some obese patients IR precedes obesity and indicate that these individuals are most likely to develop metabolic syndrome and T2DM.(10) These data and arguments form a basis for the "neurocentric" model of the pathogenesis of IR, diabetes and obesity in which the reduction in the neuronal signals received by food intake and/or from the adipose tissue may cause hepatic IR and a positive energy balance which worsens the IR, eventually leading to the exhaustion of the pancreatic $\beta$-cells and the development of T2DM.(11)

\section{METABOLIC SYNDROME IN CHILDHOOD}

In childhood obesity, findings similar to those in adults, like central obesity, female gender, family history, acanthosis nigricans and uncontrollable appetite are documented. The proceedings of the recently published "Pediatric Metabolic Syndrome Working Group (PMSWG)" reflects the ongoing discussions and debates on the definitive criteria for diagnosis of childhood obesity and the assessment of risks for future adverse developments.(12) The important questions put forward concern whether the child with metabolic syndrome is a candidate for T2DM; what the risks for the development of these disorders in adulthood are; why the diagnosis of metabolic syndrome is important and what the consensus on the 
diagnostic criteria are; whether the right diagnostic criteria for glucose intolerance should be a fasting blood glucose (FG) cut off value of $\geq 110 \mathrm{mg} / \mathrm{dL}$ vs $\geq 100 \mathrm{mg} / \mathrm{dL}$, whether the 120 minute level of $\geq 140 \mathrm{mg} / \mathrm{dL}$ in oral glucose tolerance test (OGTT) are adequate criteria, or whether the criteria should include insulin levels. Further questions to be answered include whether metabolic syndrome is seen in nonobese children and should children be screened for this; and whether the development of glucose intolerance and T2DM in the metabolic syndrome phenotype can be prevented.

\section{Diagnosis of the metabolic syndrome}

The conclusions on the prevalence of metabolic syndrome in childhood vary depending on whether the "childhood cut off values' given by the criteria of the NCEP or merely the BMI $\mathrm{z}$ scores are used. ${ }^{13}$ For example, the prevalence of metabolic syndrome amongst obese children has been reported as 44.2\%*, 26.2\%, $14.1 \%$ and $12.4 \%$ in different studies, while the respective values for prevalence of metabolic syndrome in children with the risk of obesity vs the normal controls have been given as $7.8 \%$ vs $1.6 \% *, 0 \%$ vs $0 \%, 0 \%$ vs $0 \%$ and $5.8 \%$ vs $1.1 \%$.(13) Within these series of results, those reported by Cook and Ford (*marked by) are based on the NCEP criteria, namely a fasting blood glucose cut off value of $\geq 100$ $\mathrm{mg} / \mathrm{dL}$, while the rest have used the cut off value of $\geq 110 \mathrm{mg} / \mathrm{dL}$. The variability observed in the results quoted has made the use of the cut off value of $\geq 100 \mathrm{mg} / \mathrm{dL}$ debatable(14) although this has been recommended both in the NCEP and in the IDF 2005 report. (5) The diagnostic use of the impaired fasting glucose (IFG) value with other parameters of glucose intolerance singly or together, and the relationship between these and the ratio of IR to insulin secretion are still being debated. Taking the criterion of IFG $\geq 110 \mathrm{mg} / \mathrm{dL}$ as diagnostic, it has been reported that the FG in 30\% of the cases of undiagnosed T2DM was normal; the IFG of less than $0.8 \%$ of obese children with impaired glucose tolerance (IGT) was in the range $110-125 \mathrm{mg} / \mathrm{dL}$; and, among 710 obese Italian children, 30 (4.2\%) had IGT, and only $3(0.4 \%)$ had IFG, two of these also having IGT.(15, 16, 17, 18) In an investigation with obese adolescents on the relation of IFG and IGT, taken singly and together, to insulin sensitivity and insulin secretion by using the 'hyperinsulinemic-euglycaemic clamps' technique, it was found that peripheral insulin sensitivity in those with normal FG and IFG were similar, but significantly lowered in those with IGT and IFG+IGT; whereas the hepatic IR was significantly raised in the IFG, IGT and the IFG+IGT groups.(19) In the same study, while glucose sensitivity after the first phase insulin release was lowered in the IFG, IGT and IFG+IGT groups, it was lowered during the second phase secretion only in the IFG+IGT group. Here, the apparent relation of hepatic insulin sensitivity and the glucose sensitivity to the first phase of insulin secretion in the IFG group; the reduction of the first phase insulin secretion and the significant rise in peripheric IR in the IGT group, and the marked IR with reduction in both phases of insulin secretion are noteworthy.(19) Therefore, OGTT is recommended for children under the risk of developing T2DM.(18)

There is accumulated evidence for the close relationship between obesity and metabolic syndrome in childhood. The mean prevalence of metabolic syndrome has been found to be $31 \%$ among obese black subjects compared to $0.7 \%$ in the nonobese, and $42.9 \%$ among obese white subjects as compared to $2.8 \%$ in the nonobese.(20) Although different parameters are being used to diagnose obesity, it is accepted that circumference of the waist, as a measure of visceral adiposity, is a determining sign of IR, serum lipid profile and hypertension. $(21,22)$ Also it has been shown that among youth with matching BMI values, those with higher visceral fat had lower insulin sensitivity.(22) On the basis of these data, the definite criterion 
proposed by IDF for diagnosis of childhood metabolic syndrome is a waist measurement $>90^{\text {th }}$ percentile. (23) The new IDF diagnostic criteria for childhood metabolic syndrome have been presented in Table 1 .

\section{Pathogenesis}

As in the adult cases, the factors most stressed in the pathogenesis of childhood metabolic syndrome are obesity and IR. In an investigation of the obesity grade and the prevalence of metabolic syndrome among adolescents, the prevalence of metabolic syndrome was shown to be $38.7 \%$ in the moderately obese (BMI z score of 2-2.5), and 49.7\% among the severely obese (BMI $z$ score of $>$ 2.5). Also, the C-reactive protein level was found to be increased with increasing grade of obesity while the adiponectin level was decreased.(16) C-reactive protein level has been accepted as a sign of inflammation associated with cardiovascular morbidity. Each 0.5 point increase in BMI has been calculated to increase metabolic syndrome prevalence by 1.55 . When results are corrected for ethnic factors and grade of obesity, significant increase in prevalence of metabolic syndrome is seen with escalating IR. In a prospective study on the risks of CVD among Finnish youth, the incidence of metabolic syndrome was found to be associated with higher initial insulin levels.(24)
Although the close link between obesity and metabolic syndrome is accepted, it has not been possible to explain why some obese children do not present with the condition. In the Third National Health and Nutrition Examinaton Survey III (NHANES III), which is the study with the widest scale of investigation on the epidemiology of childhood metabolic syndrome, metabolic syndrome was not found in $70 \%$ of obese children tested. In a recent study with adolescents, designed to explain this result of the NHANES III, analysis of results making corrections for the effects of obesity have shown that in those cases with metabolic syndrome insulin sensitivity had fallen by 62\%.(25) These results suggest that metabolic syndrome is not a simple result of obesity but an independent pathological development that surfaces with IR. The fast development of T2DM in 8 patients with IFG has been documented in 8 patients.(16) The increase in the incidence of T2DM worldwide among children should be treated as the tip of the iceberg, and attention should be directed to the components of metabolic syndrome like chronic low grade inflammation implicated in the epidemiology of CVD.

In a recent study it has been stressed that obesity comes to the fore as the leading influence behind metabolic syndrome which is characterised with widened waist circumference, increased visceral adiposity, hyperten-

Table 1: International Diabetes Federation criteria for identification of the metabolic syndrome and of risk groups in children and adolescents

Age 6 -10 years

- Obesity: Waist circumference $\geq 90^{\text {th }}$ percentile for age

- Although a diagnosis of metabolic syndrome cannot be made in this age group, measurements should be made on those with a family history of T2DM, metabolic syndrome, dyslipidemia, cardiovascular disease, hypertension, and obesity

Age $10-16$ years

- Obesity: Waist circumference $\geq 90^{\text {th }}$ percentile for age (for lower values, the adult threshold value) plus

- Triglycerides $\geq 150 \mathrm{mg} / \mathrm{dL}$

- HDL-cholesterol $<40 \mathrm{mg} / \mathrm{dL}$

- Blood pressure $\geq 130 \mathrm{mmHg}$ systolic or $\geq 85 \mathrm{mmHg}$ diastolic

- Fasting blood glucose $\geq 100 \mathrm{mg} / \mathrm{dL}$ (OGTT recommended) or known T2DM

Age $>16$ years

- Use adult IDF criteria. 
Table 2: The clinical features of childhood metabolic syndrome

- Family history of diabetes, obesity, hypertension, cardiovascular disease and/or stroke

History of gestational diabetes of the mother

- Low birth weight (frequent)

- Excess birth weight (rare)

- Asthma/allergic rhinitis

- Premature pubarche

- Red (new) and white (old) stria

- Obesity development with adrenarche or the progression of obesity

- Reduced energy expenditure at rest

- A decrease in fat and carbohydrate oxidation at rest

- Acanthosis nigricans

- Tall stature/pseudoacromegaly

- Hirsutism /PCOS development at adolescence

- Adipomasty/gynecomasty

- Acute pancreatitis

- Early atherosclerosis

- Hypertension/glomerulonephritis

- T2DM

sion, and with hyperinsulinism and hypoadiponectinaemia which can be used as the very indicators of metabolic syndrome.(20)

The clinical features of metabolic syndrome of childhood are similar to a large extent to those of adulthood and have been presented in Table 2.(26)

\section{The development of T2DM with} childhood metabolic syndrome and determination of risks in adulthood

Although the interrelationship between obesity and metabolic syndrome and the development of T2DM in childhood and adolescence is accepted, the details of the metabolic processes behind this development are not yet clear. In the sample cases where progression from normal glucose tolerance to T2DM occurs, a strong relationship between IR and visceral obesity, a compensation of IR initially with hyperinsulinism, and the progress from IGT in the presence of IR towards T2DM, with the gradual exhaustion of the pancreatic $\beta$-cells by different factors like glucotoxicity and lipotoxicity, have been discussed.(18, 27)

In children with newly diagnosed T2DM, a decrease of $50 \%$ in insulin sensitivity and a
$75 \%$ reduction in the first phase of insulin secretion with a severe insufficiency of the $\beta$-cell functions as compared to that in adults have been shown. The children under risk of developing T2DM experience a faster weight gain during passage to IGT which gets more severe when presenting with overt T2DM. The studies show that during the development of T2DM the failure of $\beta$ cell functions take place at twice the rate seen in the adult cases.(18)

In a study evaluating the risk of adulthood T2DM created by childhood metabolic syndrome, it was assessed that $68 \%$ of those with childhood metabolic syndrome had metabolic syndrome at adulthood and that 15.6\% developed T2DM, while a lower proportion $(24 \%)$ of those who did not have childhood metabolic syndrome developed metabolic syndrome as adults and 5\% of these children developed T2DM.(28) This study has provided important indicators for metabolic syndrome in adults such as childhood metabolic syndrome, family history of T2DM, age, increase in BMI with age, and indicators for T2DM such as childhood metabolic syndrome, age, black ethnicity and family history of T2DM. 


\section{Obsevations in Turkey}

Compared to previous years, at present more cases of T2DM are encountered in pediatric endocrinology departments around the country. Also, obesity and metabolic syndrome which constitute the highest risks for T2DM have increased very significantly in Turkey. In a recent study with school children in the Kocaeli area in western Turkey, an $11.5 \%$ prevalence of obesity risk, and $6.8 \%$ of frank obesity with a risk for metabolic syndrome in $28.1 \%$ of this subpopulation has been reported.(29) In other studies, prevalence figures of $27 \%$ for metabolic syndrome and $17 \%$ for IGT have been reported. $(30,31)$ In our pediatric obesity clinic, $8.9 \%$ of these children were found to have IGT and $25.5 \%$ of those with a family history of T2DM were found to be prediabetic. $(32,33)$

Although, given the currently available data, the ethnically different groups in Turkey do not present a special risk for T2DM, it is not difficult to guess that in the coming 30 years T2DM can become a serious problem among the children.

\section{REFERENCES}

1. Karelis AD. St-Pierre DH, Conus F, Rabasa-Lhoret R, Poehlman ET. Metabolic and body composition factors in subgroups of obesity: what do we know? J Clin Endocrinol Metab. 2004;89:2569-2575. [Abstract / Full Text / PDF]

2. Reaven GM. Banting Lecture 1988. Role of insulin resistance in human disease. Diabetes 1988;37:1595-1607. [Abstract]

3. Alberti KG, Zimmet PZ. WHO Consultation. Definition, diagnosis and classification of diabetes mellitus and its complications, Part I: diagnosis and classification of diabetes mellitus provisional report of a WHO consultation. Diabet Med 1998;15:539-553. [Abstract / PDF]

4. Expert Panel on Detection Evaluation, and Treatment of High Blood Cholesterol in Adults. Executive Summary of the Third Report of the National Cholesterol Education Program (NCEP) Expert Panel on Detection, Evaluation, and Treatment of High Blood Cholesterol in Adults (Adult Treatment Panel III). JAMA 2001;285:2486-2497. [Abstract / Full Text / PDF]

5. Alberti KGMM, Zimmet PZ, Shaw J. The metabolic syndrome-a new world-wide definition from the International Diabetes Federation Consensus. Diabet Med 2006;23:1385-1386. [Abstract]

6. Metabolic syndrome-a new world-wide definition. A Consensus Statement from the International Diabetes Federation. [Abstract / Full Text / PDF]

7. Kaufman FR, Shaw J. Type 2 diabetes in youth: rates, antecedents, treatment, problems and prevention. Pediatr Diabetes. 2007;8(Suppl 9):4-6. [Abstract / Full Text / PDF]

8. Kahn R, Buse J, Ferrannini E, Stern M. The metabolic syndrome: time for a critical appraisal: joint statement from the American Diabetes Association and the European Association for the Study of Diabetes. Diabetes Care 2006;29:177-178. [Full Text / PDF]

9. Reaven $\mathrm{G}$. The metabolic syndrome or the insulin resistance syndrome? Different names, different concepts, and different goals. Endocrinol Metab Clin North Am 2004; 33:283-303. [Abstract / Full Text / PDF]

10. Biddinger SB, Kahn CR. From mice to men: insights into the insulin resistance syndromes. Ann Rev Physiol 2006;68:123-158. [Full Text / PDF]

11. Lustig R. Which Comes First? The Obesity or the Insulin? The Behavior or the Biochemistry? J Pediatr 2008;152:601-602. [Abstract / Full Text / PDF]

12. Schwartz MW. Porte D Jr. Diabetes, obesity, and the brain. Science 2005;307(5708):375-379. [Full Text / PDF]

13. Huang T. Finding Thresholds of Risk for Components of the Pediatric Metabolic Syndrome. J Pediatr 2008;152:158-159. [Abstract / Full Text / PDF]

14. Cook S, Auinger P, Li C, Ford ES. Metabolic Syndrome Rates in United States Adolescents, from the National Health and Nutrition Examination Survey, 1999-2002. J Pediatr 2008;152:165-170. [Abstract / Full Text / PDF] 
15. Shaibi GQ, Goran MI. Examining Metabolic Syndrome Definitions in Overweight Hispanic Youth: A focus on insulin resistance. J Pediatr 2008;152:171-176. [Full Text]

16. Shaw JE, Zimmet PZ, McCarthy D, de Courten M. Type 2 diabetes worldwide according to the new classification and criteria. Diabetes Care 2000; 23(suppl.2):B5-B10. [Abstract / Full Text / PDF]

17. Sinha R, Fisch G, Teague B, Tamborlane WV, Banyas B, Allen K, Savoye M, Rieger V, Taksali S, Barbetta G, Sherwin RS, Caprio S. Prevalence of impaired glucose tolerance among children and adolescents with marked obesity. N Engl J Med 2002;346:802-810. [Abstract / Full Text / PDF]

17. Invitti C, Guzzaloni G, Gilardini L, Morabito F, Viberti G. Prevalence and concomitants of glucose intolerance in European obese children and adolescents. Diabetes Care 2003;26:118-124. [Abstract / Full Text / PDF]

18. Libman IM, Arslanian SA. Prevention and Treatment of Type 2 Diabetes in Youth. Horm Res 2007;67:22-34. [Abstract / Full Text / PDF]

19. Cali AMG, Bonadonna RC, Trombetta M, Weiss R, Caprio S. Metabolic abnormalities underlying the different prediabetic phenotypes in obese adolescents. J Clin Endocrinol Metab. 2008;93:17671773. [Full Text / PDF]

20. Lee S, Bacha F, Güngör N, Arslanian S. Comparison of different definitions of pediatric metabolic syndrome:relation to abdominal adiposity, insulin resistance, adiponectin, and inflammatory biomarkers. J Pediatr 2008;152:177-184. [Abstract / Full Text / PDF]

21. Lee S, Bacha F, Arslanian SA. Waist circumference, blood pressure, and lipid components of the metabolic syndrome. J Pediatr 2006;149:809-816. [Abstract / Full Text / PDF]

22. Bacha F, Saad R, Gungor N, Arslanian SA. Are obesity-related metabolic risk factors modulated by the degree of insulin resistance in adolescents? Diabetes Care 2006;29:1599-1604. [Abstract / Full Text / PDF]

23. Zimmet P, Alberti KGMM, Kaufman F, Tajima N, Silink M, Arslanian S, Wong G, Bennett P, Shaw J, Caprio S. The metabolic syndrome in children and adolescents - an IDF consensus report. Pediatr Diabetes. 2007;8:299-306. [Abstract / Full Text / PDF]

24. Raitakari OT, Porkka KVK, Rönnemaa T, Knip M, Uhari M, Akerblom HK, Viikari JSA. The role of insulin in clustering of serum lipids and blood pressure in children and adolescents. The Cardiovascular Risk in Young Finns Study. Diabetologia 1995;38: 1042-1050. [Abstract]

25. Cruz ML, Weigensberg MJ, Huang TTK, Ball G, Shaibi GQ, Goran MI. The metabolic syndrome in overweight Hispanic youth and the role of insulin sensitivity. J Clin Endocrinol Metab 2004;89:108113. [Abstract / Full Text / PDF]

26. Ten S, Maclaren N. Insulin resistance syndrome in children. J Clin Endocrinol Metab 2004; 89: 25262539. [Abstract / Full Text / PDF]

27. Saad R, Güngör N, Arslanian S. Progression from normal glucose tolerance to type 2 diabetes in a young girl: longitudinal changes in insulin sensitivity and secretion assessed by the clamp technique and surrogate estimates. Pediatric Diabetes 2005;6:95-99. [Abstract / Full Text / PDF]

28. Morrison JA, Friedman LA, Wang P, Glueck CJ. Metabolic syndrome in childhood predicts adult metabolic syndrome and type 2 diabetes mellitus 25 to 30 years later. J Pediatr. 2008;152:201-206. [Abstract / Full Text / PDF]

29. Çizmecioğlu, Etiler N, Erdönmez D, Hamzaoğlu O, Hatun S. Prevalence of metabolic syndrome in schoolchildren in Turkey: A population based study. ESPE 45th Annual Meeting, Rotterdam, JuneJuly 2006.

30. Atabek ME, Pirgon O, Kurtolu S. Prevalence of metabolic syndrome in obese Turkish children and adolescents. Diabetes Res Clin Pract. 2006;72:315-321. [PDF]

31. Atabek ME, Pirgon O, Kurtolu S. Assessment of abnormal glucose homeostasis and insulin resistance in Turkish obese children and adolescents. Diabetes Obes Metab. 2006;9:304-310. [Abstract / Full Text / PDF]

32. Çizmecioğlu F, Hatun S, Kalaça S. Metabolic syndrome in obese Turkish children and adolescents: comparison of two diagnostic models. Turk J Pediatr 2008;50:359-365.

33. Babaoğlu K, Hatun S, Arslanoğlu, Işgüven, Baş, Ercan O, Darendeliler F, Bundak R, Saka N, Günöz $H$, Bereket A, Memioğlu NN, Neyzi O. Evaluation of glucose intolerance in adolescents relative to adults with type 2 diabetes mellitus. J Pediatr Endocrinol Metab. 2006;19:1319-1326. [Abstract] 